\title{
Desempenho, variáveis fisiológicas e comportamento de bezerros mantidos em diferentes instalações: época seca ${ }^{1}$
}

\author{
Daniel de Noronha Figueiredo Vieira da Cunha ${ }^{2}$, Oriel Fajardo de Campos ${ }^{3}$, José Carlos \\ Pereira $^{4}$, Maria de Fátima Avila Pires ${ }^{3}$, Rita Flávia Miranda de Oliveira ${ }^{4}$, Janaina Azevedo \\ Martuscello ${ }^{2}$
}

\footnotetext{
1 Parte da dissertação de Mestrado do primeiro autor.

2 Pós-graduando em Zootecnia - UFV.

${ }^{3}$ Embrapa Gado de Leite.

${ }^{4}$ Departamento de Zootecnia da UFV.

5 PESAGRO - RJ.
}

RESUMO - Objetivou-se neste estudo avaliar o desempenho, o conforto térmico e o comportamento de bezerros mestiços Holandês $\times$ Zebu mantidos em abrigos móveis, sob sombrites ou a céu aberto durante a época seca do ano (26/04/2002 a 30/08/2002). Foram utilizados 24 bezerros do nascimento aos 70 dias de idade, distribuídos em blocos casualizados, nas instalações: 1 - abrigos móveis; 2 - sob telas de polipropileno (sombrite); 3 - a céu aberto. Os animais mantidos a céu aberto apresentaram, à tarde, maior temperatura retal e maior frequência respiratória. Não foram observadas diferenças entre intalações quanto às variáveis relacionadas ao comportamento animal. Bezerros mantidos em abrigos móveis passaram a maior parte do tempo fora das instalações. O desempenho dos animais não diferiu entre os tratamentos. Nos três tipos de instalação, os bezerros intensificaram, à tarde, os mecanismos latentes de perda de calor elevando a frequência respiratória acima da faixa considerada normal. Os animais mantidos a céu aberto não conseguem manter a temperatura retal na faixa considerada normal. Bezerros mantidos em abrigos móveis, sob telas de polipropileno ou a céu aberto apresentam desempenhos semelhantes.

Palavras-chave: abrigos, conforto térmico, frequência respiratória, temperatura retal

\section{Performance, physiological and behavioral measurements of dairy calves in different housing systems: dry season}

\begin{abstract}
The objective of this trial was to evaluate performance, thermal comfort and behavior of crossbred Holstein x Zebu dairy calves kept in different housing systems during the dry season (26/04/2002 to 30/08/2002). Twenty-four calves were raised from birth to 70 days of age in one of the following housing systems: (1 - hutches; 2 - shadecloth; or 3 - with no shelter. Calves raised with no shelter showed higher rectal temperatures and respiratory rates in the afternoon. It was also observed that calves spend most of the time outside the hutches. There were no differences among housing systems for behavior measurements as well as for body weight, average daily weight gain, starter intake, and feed efficiency. In all three housing systems calves used their latent heat loss mechanisms by increasing respiratory rates above normal range in the afternoon. Calves raised with no shelter showed increased rectal temperatures and respiratory rates and were not able to maintain these variables within normal physiological range. No significant differences in calf performance were observed across the three housing systems in the present study.
\end{abstract}

Key Words: hutches, rectal temperature, respiratory rate, thermal comfort

\section{Introdução}

No início do século XX, a criação de bezerros de rebanhos leiteiros em galpões ou estábulos fechados nos Estados Unidos era comum, em virtude das baixas temperaturas durante os invernos. Buckley (1913) associou a incidência de doenças nos animais à baixa luminosidade, à insuficiente renovação de ar e à alta umidade no interior dos estábulos fechados. Esse autor observou que a criação de animais em galpões abertos apresentou algumas vantagens, como menor imobilização de capital na construção das instalações, maior limpeza do ambiente e maior conforto e sanidade dos animais.

Na década de 1950, a utilização de instalações abertas era bastante difundida (Murley \& Culvahouse, 1958) e alguns pesquisadores vislumbravam o uso de abrigos móveis em substituição aos galpões e estábulos na criação de bezerros. Os primeiros relatos sobre a utilização de abrigos 
móveis na criação de bezerros de rebanhos leiteiros datam desta década, quando Davis et al. (1954) estudaram a possibilidade de bezerros serem criados ao ar livre. Esses autores observaram que, mesmo em condições de inverno rigoroso, com temperatura ambiente de $-15^{\circ} \mathrm{C}$, os bezerros criados em abrigos móveis apresentaram maior ganho de peso, menor ocorrência de problemas respiratórios e menor taxa de mortalidade em comparação aos mantidos em baias.

Nos anos posteriores, muitas pesquisas foram realizadas para avaliar o desempenho de bezerros criados em abrigos móveis em condições de clima temperado (Murley \& Culvahouse, 1958; Kurtz, 1961; Willett et al., 1968; Jorgenson et al., 1970; Freeman et al., 1975; Mcknight, 1978).

A popularização do uso de abrigos móveis em regiões de clima temperado ocorreu na década de 1980. Segundo Heinrichs et al. (1987), em levantamento feito nos anos de 1984 e 1985, os abrigos móveis eram utilizados em aproximadamente metade das propriedades da Pensilvânia.

No mesmo período, alguns pesquisadores brasileiros propuseram a utilização destas instalações em condições tropicais. Campos et al. (1992) compararam o desempenho de bezerros criados em baias e em abrigos móveis e relataram que, apesar de o tipo de instalação não ter influenciado o desempenho dos animais durante o inverno, no verão os bezerros criados em baias apresentaram maior ganho de peso e maior consumo de concentrado.

No Brasil, embora a utilização de abrigos móveis seja largamente recomendada, há pouca informação sobre sua utilização. Tem-se observado que, em condições tropicais, os bezerros passam a maior parte do tempo fora dos abrigos e que, mesmo nos horários de radiação solar mais intensa ou durante fortes chuvas, os animais pouco utilizam as instalações e mantêm-se, na maior parte do tempo, expostos às intempéries. Recentes pesquisas têm permitido questionar a necessidade da utilização dos abrigos móveis em condições tropicais. Moron et al. (2002) observaram que bezerros mantidos em abrigos móveis ou apenas sob proteção de palmeiras apresentavam desempenhos semelhantes.

Neste estudo, objetivou-se avaliar o desempenho, o conforto térmico e o comportamento de bezerros de rebanhos leiteiros mantidos em abrigos móveis, sob sombrites ou a céu aberto durante a época seca do ano.

\section{Material e Métodos}

O experimento foi conduzido no Campo Experimental Santa Mônica (CESM), da Embrapa Gado de Leite, situado no distrito de Barão de Juparanã, em Valença-RJ, no período de 26/04/2002 a 30/08/2002.
Foram utilizados 24 bezerros mestiços Holandês $\times$ Zebu, de grupamentos genéticos que variaram de $1 / 2$ a 15/16 Holandês, nascidos no CESM e na Estação Experimental de Itaguaí da PESAGRO-RJ. Os animais permaneceram no experimento do nascimento aos 70 dias de idade. Ao nascimento, foram distribuídos em delineamento experimental de blocos casualizados, com três instalações e oito repetições, de modo que cada animal foi considerado uma unidade experimental. Na formação dos blocos, foram considerados o sexo, a semana de nascimento e o grupamento genético dos animais.

Foram testadas as seguintes instalações: 1 - abrigos individuais móveis, fechados lateralmente com bambu e cobertos com telhas de zinco; 2 - abrigos alternativos feitos com moirões de eucalipto, sem proteção lateral e cobertos com telas de polipropileno (sombrites), com $70 \%$ de sombreamento; e 3 - a céu aberto.

Todos os animais foram contidos por meio de cordas com 1,8 m de comprimento, com uma das extremidades fixada ao solo e outra acoplada a uma coleira, de forma a não permitir o contato físico entre eles.

Os abrigos individuais móveis (1,2 $\mathrm{m}$ de comprimento $\times 1,0 \mathrm{~m}$ de largura $\times 1,1 \mathrm{~m}$ de altura) foram dispostos no sentido noroeste - sudeste para que o interior ficasse protegido das chuvas predominantes, porém permitindo a incidência de radiação solar direta durante as primeiras horas do dia. Os sombrites possuíam 1,5 m de largura, 4,0 m de comprimento e foram sustentados a $1,5 \mathrm{~m}$ do solo.

Os bezerros foram apartados de suas mães 24 horas após o nascimento e receberam $4 \mathrm{~L}$ de colostro/animal/dia até o 3 o dia de vida, em duas refeições diárias (manhã e tarde). Do 40 ao 15 - dia de vida, os bezerros receberam $4 \mathrm{~L}$ de leite integral/animal/dia, em duas refeições diárias (manhã e tarde). A partir do 16을a, os animais receberam $4 \mathrm{~L}$ de leite integral/animal/dia, em apenas uma refeição diária, à tarde. A dieta líquida foi fornecida em baldes e o desaleitamento foi realizado, abruptamente, aos 57 dias de idade.

A partir da 1a semana de vida, todos os bezerros receberam, em cochos cobertos, concentrado inicial com 87\% de MS (mínimo); 16\% de PB (mínimo); 6,7\% de matéria fibrosa (máximo); 1,5\% de Ca (máximo)e 0,4\% deP (mínimo), segundo informações do fabricante. O concentrado foi fornecido na proporção de até $2,0 \mathrm{~kg} / \mathrm{animal} /$ dia e todos os animais tiveram livre acesso à água, disponibilizada em baldes plásticos com capacidade para $10 \mathrm{~L}$. Não foi fornecido volumoso aos animais.

Os animais foram pesados semanalmente. Ao nascimento, ao desaleitamento e no final do período experimental, foram realizadas pesagens durante três dias consecutivos utilizando-se a média obtida das três pesagens. 
O consumo de concentrado foi avaliado diariamente e calculado como a diferença entre o peso do fornecido e o peso das sobras. O consumo de água foi medido na $1 \underline{a}$, $4 \underline{a} \underline{a}$ e 9a semanas de vida e correspondeu à diferença entre o volume oferecido e o volume residual.

A ocorrência de diarréias foi observada diariamente. Às fezes consideradas normais, foi atribuído o valor 1 e às diarréicas, o valor 2.

As avaliações relacionadas ao comportamento foram realizadas por meio de aferições visuais, com três observadores revezando-se em turnos de 6 horas. Os animais foram observados durante a $1^{\mathrm{a}}$, a $4^{\mathrm{a}}$ e a $9^{\underline{a}}$ semana de idade por períodos de 24 horas. Os padrões de atividade dos animais foram registrados a cada 10 minutos sendo anotados os tempos de permanência ao sol e à sombra, dentro e fora dos abrigos, em pé ou deitado, em ócio ou em ruminação, assim como o tempo gasto com a ingestão de concentrado.

As avaliações fisiológicas foram realizadas na $1 \stackrel{\text { a }}{\text {, }} 4^{\mathrm{a}} \mathrm{e}$ 9a semanas de vida dos animais. Às $8 \mathrm{~h}$ e $15 \mathrm{~h}$, foram medidas a frequência respiratória e a temperatura retal dos animais. A frequência respiratória foi obtida pela contagem dos movimentos do flanco dos animais durante 30 segundos e a temperatura retal, por meio da utilização de termômetro clínico, introduzido na ampola retal, a 5,0 cm, em contato com a mucosa, até a estabilização da temperatura.

Para a caracterização do ambiente térmico em cada tipo de instalação, foram utilizados um termômetro de Vernon (Termômetro de Globo Negro) para cálculo do Índice de Temperatura do Globo e Umidade, segundo Buffington et al. (1981), e um higrômetro para cálculo do Índice de Temperatura e Umidade (ITU). As temperaturas medidas pelos termômetros foram registradas em intervalos de 1 hora, durante 24 horas, sempre nos dias das avaliações etológicas e fisiológicas. As temperaturas máxima e mínima do ar e a precipitação pluviométrica foram medidas, diariamente, no posto meteorológico do CESM, a $500 \mathrm{~m}$ do local do experimento.
Os dados referentes à temperatura retal, à frequência respiratória, ao tempo de permanência em decúbito, ao tempo de permanência em ruminação e ao tempo utilizado para ingestão de concentrado foram esquematizados em parcelas subdivididas, considerando as instalações como parcelas e as semanas de avaliação como subparcelas. Para as variáveis: tempo de exposição à radiação solar direta e tempo de permanência no interior dos abrigos móveis, foram realizadas apenas estatísticas descritivas utilizando-se o erro-padrão da média como medida de dispersão.

As médias das variáveis quantitativas foram comparadas pelo teste de Student Newman Keuls (SNK), adotando-se 5\% como nível de significância. A variável não paramétrica ocorrência de diarréias foi analisada pelo teste do Quiquadrado $\left(\mathrm{X}^{2}\right)$.

\section{Resultados e Discussão}

A precipitação pluviométrica medida nos meses de maio e agosto foi superior aos valores médios, para estes meses, dos dez anos que antecederam o período experimental (48,6 e 11,1 mm, respectivamente) (Tabela 1).

O ITU e os ITGU medidos nas instalações durante a $1 \stackrel{a}{\text {, }}$ 4므 e 9 a semanas de vida dos animais são apresentados na Figura 1. Durante a primeira semana, os valores de ITU e ITGU foram mais elevados que os da $44^{\mathrm{a}}$ e $9 \underline{a}$ semanas e, nos horários de maior intensidade de temperatura efetiva, os valores de ITGU para os animais mantidos a céu aberto foram mais elevados que para aqueles criados nas demais instalações. É importante ressaltar que, na literatura, não existem estudos sobre ITU e ITGU de conforto para bezerros mestiços Holandês x Zebu, o que impossibilita comparações adequadas.

Não houve interação $(\mathrm{P}>0,05)$ tratamento $\times$ semana para nenhuma das variáveis fisiológicas estudadas no período do nascimento aos 70 dias de idade (Tabela 2). Os tipos de instalação não influenciaram $(\mathrm{P}>0,05)$ a tempera-

Tabela 1 - Dados meteorológicos obtidos durante o período experimental

Table 1 - Meteorological data collected during the experimental period

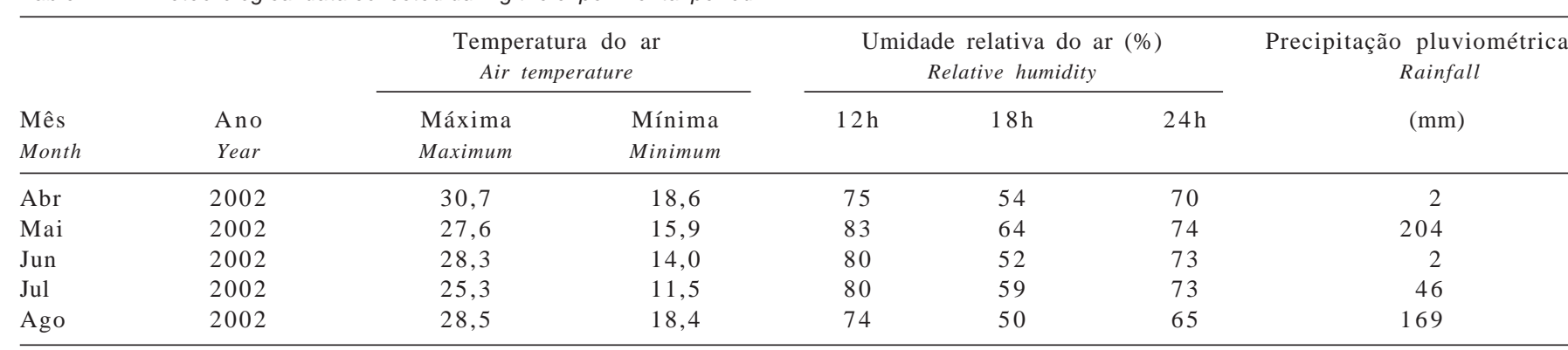

Fonte: Posto Meteorológico do Campo Experimental Santa Mônica.

Source: Meteorological Station of Santa Mônica Experimental Field. 


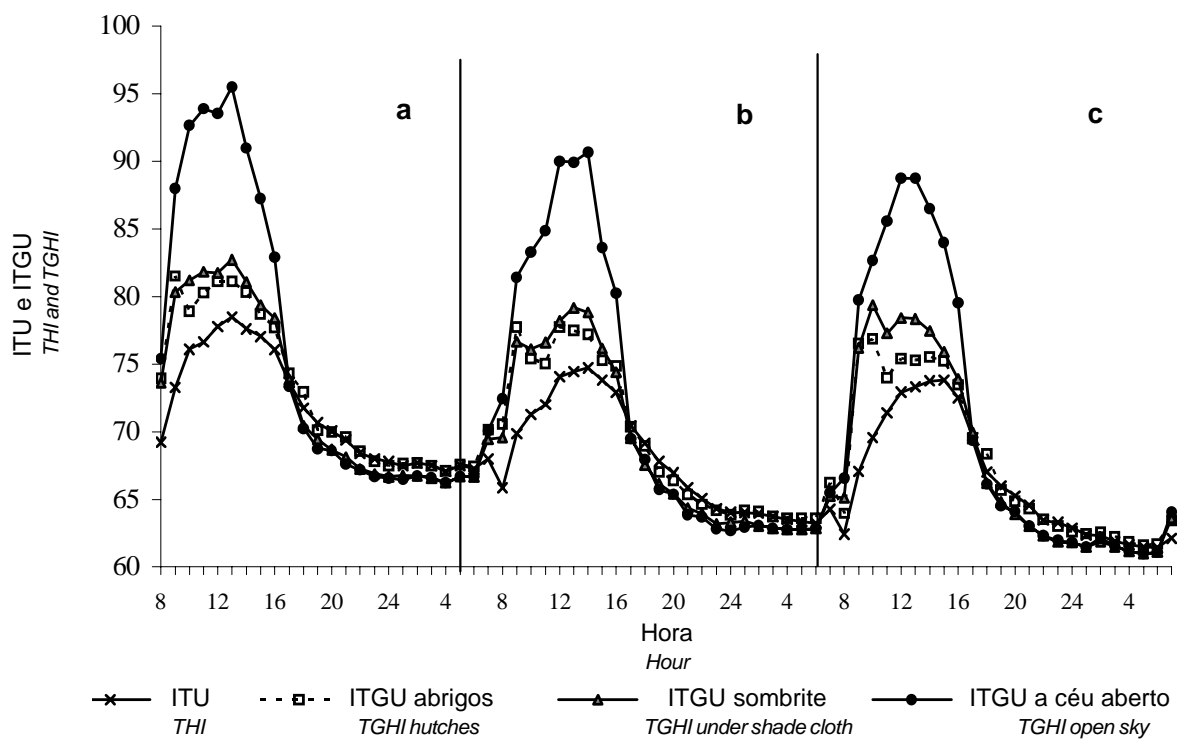

Figura 1 - Índices de temperatura e umidade (ITU) e de temperatura do globo e umidade (ITGU) nas diferentes instalações na primeira (a), quarta (b) e nona (c) semanas de vida de bezerros mestiços Holandês x Zebu.

Figure 1 - Temperature-humidity index (THI) and black globe humidity-index (BGHI) in different housing systems in the first (a), fourth (b) and ninth (c) weeks of life of crossbred dairy calves.

tura retal medida pela manhã. Brosh et al. (1998), estudando respostas de novilhas holandesas ao estresse térmico, observaram que animais desprotegidos da radiação solar direta apresentaram menor temperatura retal pela manhã em relação aos criados com acesso à sombra, o que não foi observado neste estudo. Segundo Dukes (1996), variações de 38,0 a $39,3^{\circ} \mathrm{C}$ na temperatura retal de bezerros de rebanhos leiteiros são consideradas normais.

À tarde, a temperatura retal foi maior $(\mathrm{P}<0,05)$ nos bezerros mantidos a céu aberto. Nesses animais, os valores médios de temperatura retal foram superiores aos considerados fisiologicamente normais por Dukes (1996). Outros autores observaram elevações na temperatura retal em animais expostos a radiação solar direta (Yamamoto et al., 1994; Das et al., 1999). A temperatura retal dos bezerros não foi influenciada $(\mathrm{P}>0,05)$ pelas semanas estudadas.

Não houve diferença entre os tipos de instalação $(P>0,05)$ e entre semanas $(P>0,05)$ sobre as frequências respiratórias medidas pela manhã.

A frequência respiratória medida à tarde foi maior $(\mathrm{P}<0,05)$ nos animais mantidos a céu aberto e não diferiu $(\mathrm{P}>0,05)$ entre os animais dos outros tratamentos. Os resultados indicam que os bezerros mantidos a céu aberto encontravam-se, neste período do dia, em condição de desconforto térmico, o que era previsível, pois não tinham acesso à proteção contra a radiação solar direta. É importante salientar que, em todos os animais, a frequência respiratória média observada à tarde manteve-se acima da faixa considerada normal (Dukes, 1996), evidenciando que, independentemente dos tipos de instalação, os animais intensificaram os processos latentes de perda de calor na tentativa de manterem a temperatura corporal dentro da normalidade fisiológica, embora esse mecanismo não tenha sido eficiente para os animais mantidos a céu aberto, pois a temperatura retal nesses animais manteve-se acima da faixa considerada normal.

No período da tarde, a frequência respiratória durante a primeira semana de vida dos animais foi maior $(\mathrm{P}<0,05) \mathrm{em}$ relação à observada na 4a e 9 a semanas, que não diferiram $(\mathrm{P}>0,05)$ entre si. Os valores foram de 86, 56 e 59 movimentos respiratórios por minuto na 1aㅡ $4^{\underline{a}}$ e $9^{\underline{a}}$ semanas de vida, respectivamente. De fato, durante a primeira semana de vida dos animais, os valores de ITU e ITGU foram maiores, o que pode ter ocasionado aumento na intensidade dos mecanismos latentes de perda de calor.

Não houve efeito $(\mathrm{P}>0,05)$ dos tratamentos nem da interação tratamento $\times$ semanas de vida dos animais sobre os tempos de permanência em decúbito e em ruminação e sobre o tempo de ingestão de concentrado. Entretanto, estas variáveis foram influenciadas $(\mathrm{P}<0,05)$ pela semana de vida dos animais.

Durante a primeira semana de vida, os animais permaneceram mais $(\mathrm{P}<0,05)$ tempo em decúbito $(80 \%)$ que na quarta $(73,9 \%)$ e na nona $(71,2 \%)$ semanas, que não diferiram $(\mathrm{P}>0,05)$ entre si. Esse resultado corrobora o relato de Maculay et al. (2002) de que, com o avançar da idade, os 
Tabela 2 - Frequência respiratória ( $\mathrm{n}$ o de movimentos respiratórios por minuto) e temperatura retal $\left({ }^{\circ} \mathrm{C}\right)$ pela manhã e à tarde em bezerros mestiços Holandês $\times$ Zebu mantidos em diferentes instalações ao ar livre

Table 2 - Respiratory rate (number of respiratory movements per minute) and rectal temperature $\left({ }^{\circ} \mathrm{C}\right.$ ) in the morning and afternoon of crossbred Holstein $\times$ Zebu calves kept in different housing systems

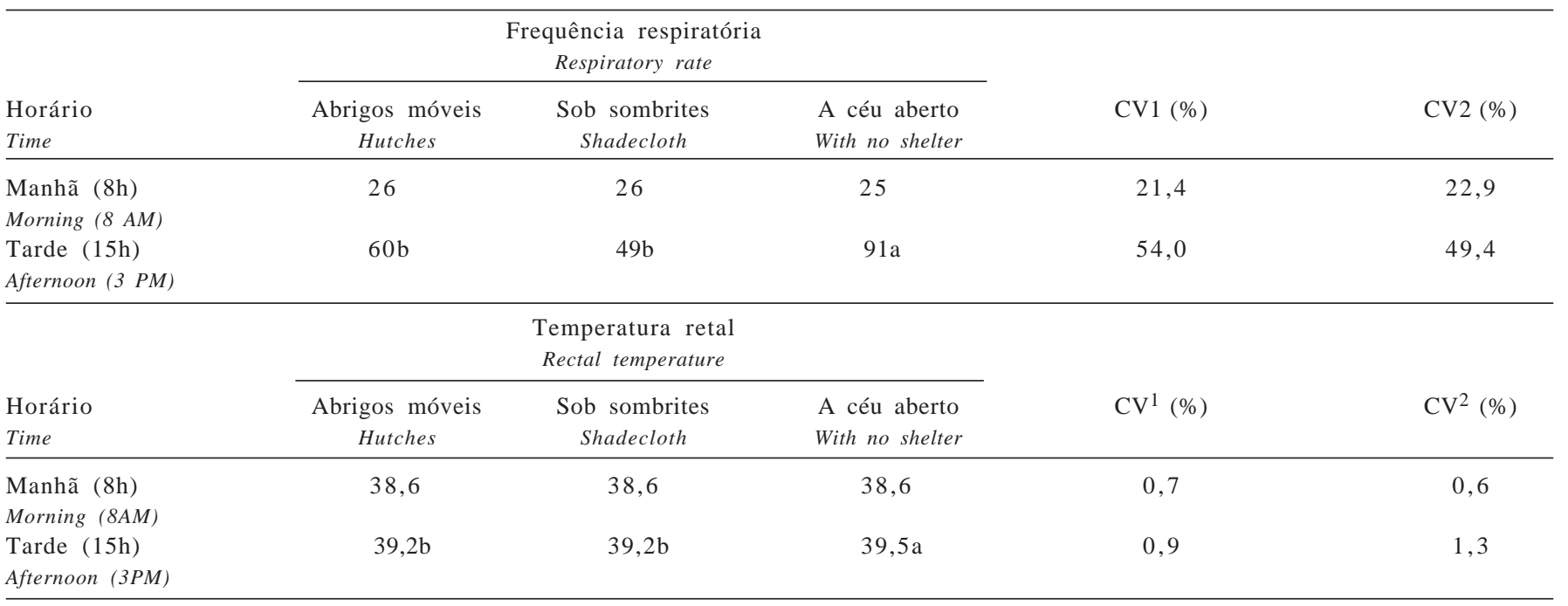

Médias na mesma linha, seguidas por letras diferentes, diferem a 5\% de significância pelo teste de SNK. CV1 = coeficiente de variação relativo às parcelas. CV2 = coeficiente de variação relativo às subparcelas.

Means in the same row followed by different letters differ at $5 \%$ by SNK test. CV1 = coefficient of variance of plots. CV2 = coefficient of variance of subplots.

bezerros tendem a permanecer menos tempo deitados. Os valores obtidos neste estudo foram semelhantes aos encontrados por Wilson et al. (1999) e Warnick et al. (1977), que verificaram que bezerros em fase de aleitamento permanecem $74 \%$ do tempo em decúbito.

Neste estudo, o tempo de permanência em decúbito foi significativamente influenciado pelo manejo alimentar (Figura 2). Numericamente, as menores porcentagens de tempo de permanência nesta atividade foram observadas às 7h30 e às 15h (horários de fornecimento da dieta líquida).
Segundo Modesto et al. (2002), quando criados no mesmo local, bezerros apresentam comportamento de intenso mimetismo. Esta característica pode explicar o fato de os bezerros desaleitados (nona semana de vida) terem continuado com o mesmo padrão de comportamento.

Durante a primeira semana de vida, não foi observada atividade de ruminação em nenhum bezerro. Da 4 a à 9a semana de vida, houve aumento $(\mathrm{P}<0,05)$ de $91 \%$ no tempo utilizado para esta atividade (4,3\% vs $8,2 \%)$. Nesse período, também houve aumento $(\mathrm{P}<0,05)$, de 2,6 para $7,8 \%$, no

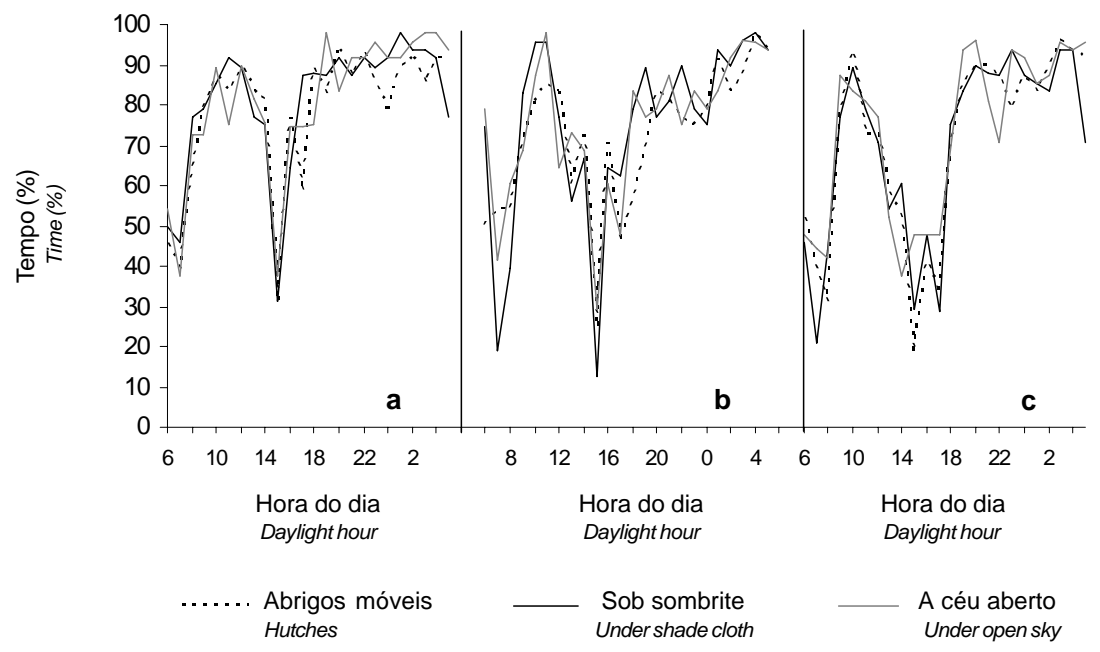

Figura 2 - Padrão de tempo de permanência em decúbito, durante 24 horas, de bezerros mestiços Holandês x Zebu mantidos em diferentes instalações na primeira (a), quarta (b) e nona (c) semanas de vida.

Figure 2 - Time pattern spent on decubitus during 24hs of crossbred Zebu x Holstein calves kept in different housing systems during the first (a), fourth (b) and ninth (c) weeks of life. 
tempo utilizado para ingestão de concentrado. O valor obtido neste estudo durante a nona semana de vida dos animais foi próximo ao de 7,6\% encontrado por Modesto et al. (2002) em bezerros mestiços Holandês $\times$ Zebu mantidos em abrigos móveis durante a fase de aleitamento.

Os bezerros mantidos nos abrigos móveis permaneceram a maior parte do tempo fora das instalações (Figura 3). Conseqüentemente, durante os horários de radiação solar mais intensa (10h às 15h), permaneceram grande parte do tempo expostos ao sol (Figura 4), o que, segundo Campos et al. (1992), poderia ser prejudicial ao desempenho dos animais.

O tempo de permanência dos animais no interior dos abrigos móveis durante as horas de chuva não foi mensurado, pois a precipitação pluviométrica nos dias das avaliações etológicas foi insignificante.

Os valores de peso vivo, ganho de peso diário, consumo diário de concentrado e eficiência alimentar encontram-se na Tabela 3. Não houve efeito $(P>0,05)$ das instalações sobre estas variáveis.

O peso ao desaleitamento foi próximo ao observado por Cunha et al. (2002), de 56,3 kg, em bezerros mestiços Holandês $\times$ Zebu desaleitados aos 56 dias de idade. É importante salientar que, no momento do desaleitamento, apesar de não ter sido detectada diferença significativa entre as instalações, os bezerros criados a céu aberto estavam, em média, $10 \%$ mais pesados que aqueles criados em abrigos móveis. Portanto, apesar de os animais mantidos a céu aberto terem apresentado maiores frequências respiratórias e temperaturas retais, a intensidade de estresse por calor não foi suficiente para afetar o ganho de peso.

O ganho de peso diário do nascimento à oitava semana de vida situou-se abaixo do encontrado por Campos et al.
(1992), de 534 g para bezerros mestiços Holandês $\times$ Zebu mantidos em abrigos móveis. Coelho (1999) observaram em bezerros da raça Holandesa criados em galpões no período após o desaleitamento (9a e 10aㅡ semanas) ganho de peso diário inferior a 874 g. Em geral, bezerros holandeses sob aleitamento artificial obtêm, em média, ganhos de peso superiores aos de mestiços Holandês $\times$ Zebu.

O consumo diário de concentrado durante o período de aleitamento (2-8 semanas) foi próximo aos $347 \mathrm{~g}$ observados por Lizieire et al. (2002), que utilizaram bezerros mestiços Holandês $\times$ Zebu mantidos em baias individuais de alvenaria. É importante ressaltar que, no momento do desaleitamento, o consumo médio de concentrado dos bezerros mantidos em abrigos móveis (610 g/animal/dia) estava abaixo dos 700 g/animal/dia preconizados por Quigley (1996) como suficientes para garantir desenvolvimento adequado dos animais.

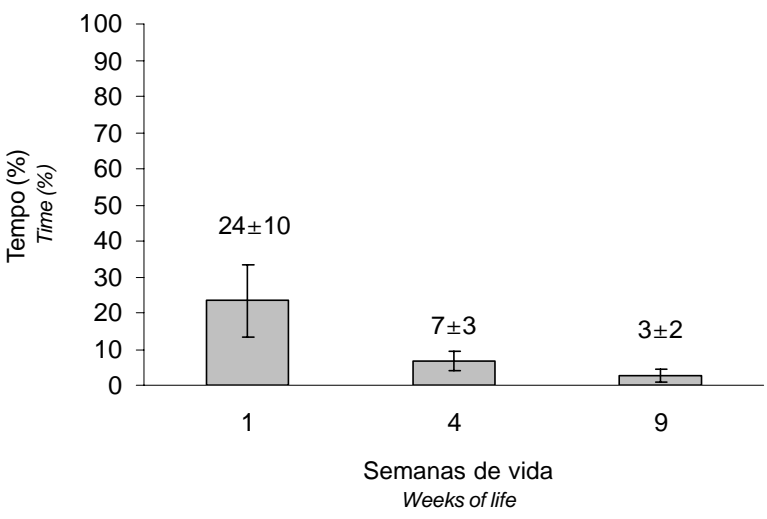

Figura 3 - Tempo de permanência de bezerros mestiços Holandês $\times$ Zebu no interior de abrigos móveis durante a primeira, à quarta e à nona semanas de vida.

Figure 3 - Time spent in mobile shelters during the first (a), fourth (b) and ninth (c) weeks of life of crossbred Holstein $x$ Zebu calves.

Tabela 3 - Desempenho de bezerros mestiços Holandês $\times$ Zebu mantidos em três diferentes tipos de instalação Table 3 - Performance of crossbred Holstein $x$ Zebu calves kept in three different housing systems

\begin{tabular}{|c|c|c|c|c|}
\hline & $\begin{array}{c}\text { Abrigos móveis } \\
\text { Hutches }\end{array}$ & $\begin{array}{c}\text { Sob sombrites } \\
\text { Shadecloth }\end{array}$ & $\begin{array}{l}\text { A céu aberto } \\
\text { With no shelter }\end{array}$ & CV $(\%)$ \\
\hline PV ao nascimento ( $\mathrm{kg} /$ animal) ( $B W$ at birth, $\mathrm{kg} /$ animal) & 33,8 & 34,5 & 35,0 & 5,0 \\
\hline PV ao desaleitamento (kg/animal) ( $B W$ at weaning, $\mathrm{kg} /$ animal) & 54,6 & 56,0 & 60,6 & 8,7 \\
\hline PV final (70 dias) (kg/animal) (Final BW 70 days, kg/animal) & 62,9 & 66,2 & 69,1 & 10,5 \\
\hline GPD (1 a 8 semanas) (g/animal/dia) (DWG 1 to 8 weeks, g/animal/day) & 392 & 415 & 469 & 25,9 \\
\hline GPD (9 a 10 semanas) (g/animal/dia) (DWG 9 to 10 weeks, g/animal/day) & 517 & 605 & 556 & 35,7 \\
\hline CDC (2 a 8 semanas) (g/animal/dia) (DCC 2 to 8 weeks, g/animal/day) & 258 & 293 & 401 & 52,6 \\
\hline CDC (9 a 10 semanas) (g/animal/dia) (DCC 9 to 10 weeks, g/animal/day) & 1424 & 1584 & 1678 & 23,7 \\
\hline EA (2 a 8 semanas) (FE, 2 to 8 weeks) & 0,548 & 0,546 & 0,568 & 18,0 \\
\hline EA (9 a 10 semanas) (FE, 9 to 10 weeks) & 0,459 & 0,440 & 0,374 & 33,1 \\
\hline CDA na 1 a semana (L) (DWC in the week $1, L)$ & 1,8 & 2,9 & 2,6 & 48,3 \\
\hline CDA na 4 a semana (L) (DWC in the week $4, L$ ) & 3,1 & 2,8 & 3,5 & 34,9 \\
\hline CDA na 9a semana $9(\mathrm{~L})$ (DWC in the week 9, $L$ ) & 5,3 & 5,3 & 6,2 & 26,4 \\
\hline
\end{tabular}

$\mathrm{PV}$ = peso vivo; GPD = ganho de peso diário; $\mathrm{CDC}$ = consumo diário de concentrado (matéria natural); $\mathrm{EA}$ = eficiência alimentar ( $\mathrm{kg}$ de ganho de peso/kg de MS consumida); $C D A$ = consumo diário de água.

$B W=$ body weight $D W G=$ daily weight gain; $D C C=$ daily concentrate consumption (fresh matter); $F E=$ feed efficiency ( $k g$ of weight gain $/ \mathrm{kg}$ of DM intake); $D W C=$ daily water consumption 


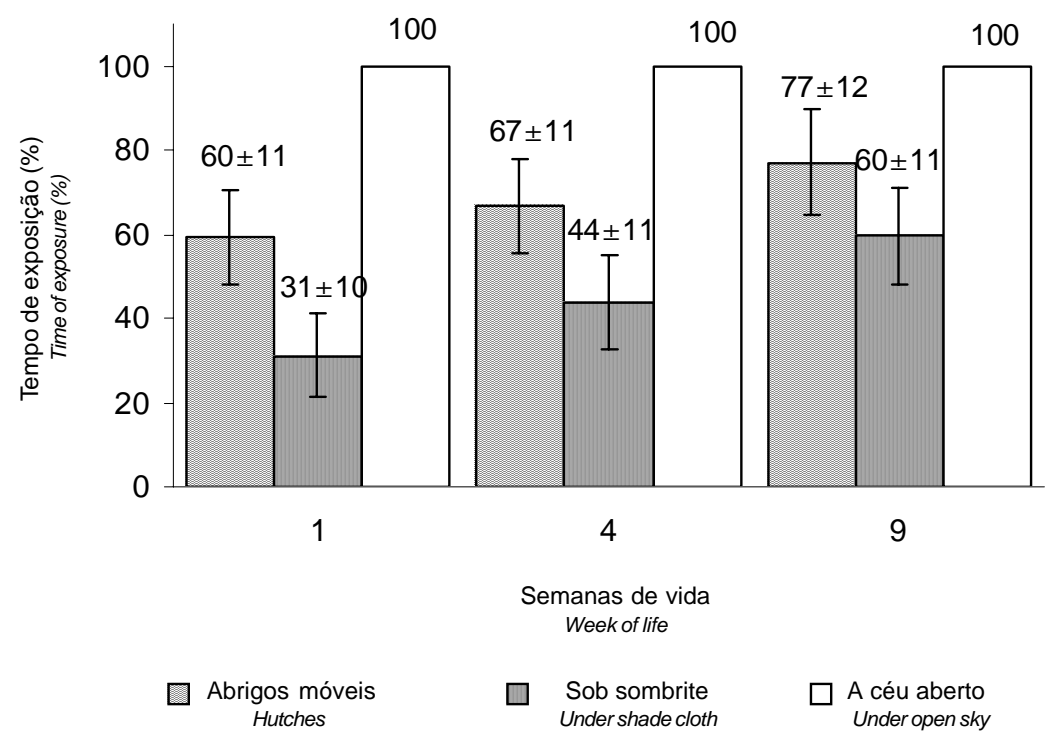

Figura 4 - Tempo de exposição à radiação solar de bezerros Holandês $\times$ Zebu na primeira, quarta e nona semanas de vida direta durante as horas de maior intensidade de radiação (de $10 \mathrm{~h}$ às 15h).

Figure 4 - Time of exposure to direct sunshine in the hours of most radiation intensity (from 10 AM to 3 PM) for crossbred Holstein x Zebu calves kept in different housing systems during the first (a), fourth (b) and ninth (c) weeks of life.

De fato, o ganho de peso diário dos animais mantidos em abrigos móveis nas semanas posteriores ao desaleitamento ( $9^{\mathrm{a}}$ e $10^{\mathrm{a}}$ semanas) foi, em valores absolutos, inferior ao dos demais.

As eficiências alimentares durante e após o aleitamento foram próximas às observadas por Lizieire et al. (2002), de 0,530 e 0,400 .

O consumo de água não foi influenciado pelos tratamentos $(\mathrm{P}>0,05)$ em nenhuma das semanas avaliadas.

$O$ teste do qui-quadrado evidenciou que a ocorrência de diarréias dependeu $(\mathrm{P}<0,01)$ dos tratamentos experimentais. Os bezerros mantidos sob sombrites tiveram diarréias em 10,1\% dos dias, enquanto aqueles mantidos nos abrigos móveis e a céu aberto foram acometidos em 6,8 e 4,6\% dos dias, respectivamente. É possível que a maior ocorrência de diarréia nos bezerros mantidos sob sombrites tenha sido ocasionada pela menor incidência de radiação solar direta na área sob estas instalações. Colleman et al. (1996), estudando a utilização de sombrites dispostos acima de abrigos móveis, no intuito de reduzir a temperatura no interior das instalações durante o verão, constataram que a cobertura suplementar favoreceu o crescimento e a multiplicação bacteriana. Neste estudo, os animais mantidos a céu aberto foram acometidos em menor freqüência por diarréias, o que pode ter influenciado positivamente o desempenho.

\section{Conclusões}

Nas condições observadas durante o período experimental, nos três tipos de instalações, na parte da tarde, os bezerros intensificam os mecanismos latentes de perda de calor, elevando a frequência respiratória acima da faixa considerada fisiologicamente normal. Animais mantidos a céu aberto não conseguem evitar que, à tarde, a temperatura retal exceda a faixa considerada fisiologicamente normal. Bezerros mantidos em abrigos móveis permanecem, na maior parte do tempo, fora das instalações e, nos horários de radiação solar mais intensa, mantêm-se na maior parte do tempo expostos ao sol. Bezerros mantidos em abrigos móveis, sob sombrites ou a céu aberto apresentam desempenhos semelhantes. Animais mantidos a céu aberto apresentam menor número de dias com diarréia.

\section{Literatura Citada}

BROSH, A.; AHARONI, Y.; DEGEN, A.A. et al. Estimation of energy expenditure from heart rate measurements in cattle maintained under different conditions. Journal of Animal Science, v.11, n.5, p.2671-2677, 1998.

BUCKLEY, S.S. Open stables versus close stables for dairy animals. Maryland: The Maryland Agricultural Experiment Station, 1913. p.219-262. (Bulletim, 177).

BUFFINGTON, D.E.A.; COLLAZO-AROCHO, G.H.; CANTON, D. et al. Black globe-humidity index (BGHI) as comfort equation for dairy cows. Transactions of the ASAE, v.24, n.4, p.711-714, 1981. 
CAMPOS, O.F.; OLIVEIRA J.S.; LIZIEIRE, R.S. Uso de abrigos como alternativa para os bezerreiros convencionais. Revista Brasileira de Zootecnia, v.21, n.5, p.954-967, 1992.

COELHO, S.G. Ganho de peso e desenvolvimento do estômago de bezerros desaleitados aos trinta dias de idade e alimentados com concentrado e com ou sem feno. Belo Horizonte. Belo Horizonte: Universidade Federal de Minas Gerais. 1999 123p. Tese (Doutorado em Zootecnia) Universidade Federal de Minas Gerais, 1999.

COLEMAN, D.A.; MOS, B.R.; McCASKEY, T.A. Supplemental shade for dairy calves reared in commercial calf hutches in a southern climate. Journal of Dairy Science, v.79, n.1, p.20382043, 1996

CUNHA, D.N.F.V.; MARTUSCELLO, J.A.; LIZIEIRE, R.S. et al. Influência da idade ao desaleitamento sobre o desenvolvimento de bezerros mestiços Holandês - Zebu. In: REUNIÃO ANUAL DA SOCIEDADE BRASILEIRA DE ZOOTECNIA, 2002, Recife. Anais... Recife: Sociedade Brasileira de Zootecnia, 2002. (CD-ROM).

DAS, S.K.; UPADHYAY, R.C.; MADAN, M.L. Heat stress in Murrah buffalo calves. Livestock Production Science, v.61, p.7178, 1999.

DAVIS, L.R.; AUTREY, K.M.; HERLICH, H. et al. Outdoor individual portable pens compared with conventional housing for raising dairy calves. Journal of Dairy Science, v.37, p.562-570, 1954.

DUKES, H.H. Fisiologia dos animais domésticos. 11.ed. Rio de Janeiro: Guanabara Koogan, 1996. 856p.

FREEMAN, R.E.; MOORE, R.B.; BROWN, W.H. et al. Housing systems for dairy calves from birth to three months. Journal of Dairy Science, v.58, n.1, p.134-134, 1975.

HEINRICHS, A.J.; GRAVES, R.E.; KIERNAN, N.E. Survey of calf and heifer housing on Pennsylvania dairy farms. Journal of Dairy Science, v.70, n.9, p.896-912, 1987.

JORGENSON, L.J.; JORGENSON N.A.; SHINGOETHE, D.S. Indoor versus outdoor calf rearing at three weaning ages. Journal of Dairy Science, v.53, n.6, p.813-816, 1970.

LIZIEIRE, R.S.; CUNHA, D.N.F.V.; MARTUSCELLO, J.A. et al. Fornecimento de volumoso para bezerros pré-ruminantes. Ciência Rural, v.32, n.5, p.835-840, 2002.

MACULAY, A.S.; HAHN, G.L.; CLARK, D.H. et al. Comparison of calf housing types and tympanic temperature rhythms in Holstein calves. Journal of Dairy Science, v.78, n.4, p.856-862, 2002.
McKNIGHT, D.R. Performance of newborn dairy calves in hutch housing. Canadian Journal of Animal Science, v.58, n.5, p.517-520, 1978.

MODESTO, E.C.; MANCIO, A.B.; DETMANN, E. et al. Aspectos comportamentais de bezerros mestiços Holandês-Zebu em aleitamento. In: REUNIÃO ANUAL DA SOCIEDADE BRASIlEIRA DE ZOOTECNIA, 39., 2002, Recife. Anais... Recife: Sociedade Brasileira de Zootecnia, 2002. (CD-ROM).

MORON, R.I.; BABILÔNIA, J.L.; OLIVEIRA, O.J. et al. Desempenho de bezerros até 60 dias de idade, criados em diferentes tipos de instalações. In: REUNIÃO ANUAL DA SOCIEDADE BRASILEIRA DE ZOOTECNIA, 39., Recife, 2002. (CD-ROM).

MURLEY, W.R.; CULVAHOUSE, E.W. Open shed and portable pens versus conventional housing for raising dairy calves. Journal of Dairy Science, v.41, p.977-981, 1958.

QUIGLEY III, J.D. Feeding prior to weaning. In: CALVES, HEIFERS AND DAIRY PROFITABILITY NATIONAL CONFERENCE, 1996, Pennsylvania. Proceedings... Ithaca: Northeast Regional Agricultural Engineering Service Cooperative Extension, 1996. p.245-255.

WARNICK, V.D.; ARAVE, C.W., MICKELSEN, C.H. Effects of group, individual, and isolated rearing of calves on weight gain and behavior. Journal of Dairy Science, v.60, n.6, p.947953, 1977.

WILLETT, L.B.; ALBRIGHT, J.L.; CUNNINGHAM, M.D. et al. Evaluation of three housing systems for raising dairy calves. Journal of Dairy Science, v.51, p.971 (Abstr.). 1968.

WILSON, L.L.; TEROSKY, T.L.; STULL, C.L. et al. Effects of individual housing design and size on behavior and stress indicators of special-fed Holstein veal calves. Journal of Animal Science, v.77, p.1341-1347, 1999.

YAMAMOTO, S.; YOUNG, B.A.; PURWANTO, B.P. et al. Effect of solar radiation on the heat load of dairy heifers. Australian Journal of Agriculture Research, v.45, n.9, p.1741-1749, 1994 